\title{
PENGARUH KOMPOSISI RESIN POLIYESTER TERHADAP KEKUATAN BENDING KOMPOSIT YANG DIPERKUAT SERAT BAMBU APUS
}

\author{
Adi Chandra ${ }^{*}$, Asroni $^{2}$ \\ Jurusan Teknik Mesin Universitas Muhammadiyah Metro \\ JI.Ki Hajar Dewantara No.166 Kota Metro Lampung 34111, Indonesia ${ }^{1,2)}$ \\ adi.chandra@yahoo.com ${ }^{1}$, asroni14@yahoo.com²
}

\begin{abstract}
Abstrak
Komposit adalah suatu material yang terbentuk dari kombinasi antara dua atau lebih material pembentuknya melalui pencampuran yang tidak homogen. Dimana sifat mekanik dari masing-masing material pembentukanya berbeda-beda. Dari pencampuran tersebut akan dihasilkan material komposit yang mempunyai sifat mekanik dan karakteristik yang berbeda dari material pembentuknya. Material yang dipakai adalah bambu apus dan bambu petung yang dimana modulus elastisitas bambu apus lebih besar dengan bambu petung. Bambu apus memiliki modulus elastisitas sebesar 23171,66 MPa, dan bambu petung mempunyai modulus elastisitas adalah 14439,64 Mpa. Alasan pemilihan serat bambu sebagai bahan baku komposit adalah mudah diperoleh dalam jumlah banyak, berkualitas, ramah lingkungan dan bernilai ekonomis. Jenis matrik yang digunakan adalah resin polyester. Jenis pengujianya adalah uji bending ASTM D-790-03. Komposisi serat dan resin 5\% : 95\%, 10\% : 90\%, 15\%: 85\%, 20\%:80\%. Variasi fraksi volume serat mempengaruhi kekuatan bending komposit, dimana kekuatan bending komposit tertinggi diperoleh pada komposit dengan fraksi volume resin $80 \%$ dan serat $20 \%$ yaitu sebesar $97,71 \mathrm{~N} / \mathrm{mm}^{2}$, sedangkan nilai kekuatan bending terendah diperoleh pada dengan fraksi volume resin $95 \%$ dan serat $5 \%$ yaitu sebesar 54,11 $\mathrm{N} / \mathrm{mm}^{2}$. Pada pola patahan komposit bending yang di uji secara mikro atau menggunakan SEM (scaning electro miscroscope) volume resin $95 \%$ dan $80 \%$ menunjukan debonding dimana lepasnya daya ikat serat dengan matrik. Matrik cracking (retak) dan fiber pull-out.
\end{abstract}

Kata kunci : Komposit, Bambu Apus, Bending, Debonding, SEM (scaning electro miscroscope)

\section{Pendahuluan}

Penelitian sebelumnya telah didapat data pengujian komposit serat gebang mengunakan fraksi volume dengan menggunakan uji tarik dimana modulus elastisitas mengalami kenaikan sampai pada komposit dengan fraksi volume serat $30 \%$ yaitu $1836,95 \mathrm{kgf} / \mathrm{mm}^{2}$, kemudian mengalami penurunan terendah pada komposit dengan fraksi volume serat $70 \%$ yaitu $1297 \mathrm{kgf} / \mathrm{mm}^{2}$.[1]

Penelitian lainnnya yaitu "Pemanfaatan material bambu sebagai alternatife bahan komposit pembuatan kulit kapal pengganti material kayu untuk armada kapal rakyat yang beroperasi di daerah maluku”. Material yang dipakai adalah bambu apus dan bambu petung yang dimana modulus elastisitas bambu apus lebih besar dengan bambu petung. Bambu apus memiliki modulus elastisitas sebesar 23171,66 $\mathrm{MPa}$, dan bambu petung mempunyai modulus elastisitas adalah 14439,64 Mpa.[2]

Komposit adalah adalah suatu material yang terbentuk dari kombinasi antara dua atau lebih material pembentuknya melalui pencampuran yang tidak homogen Komposit memiliki sifat mekanik yang lebih bagus dari logam, kekakuan jenis (modulus Young/density) dan kekuatan jenisnya lebih tinggi dari logam.[3]

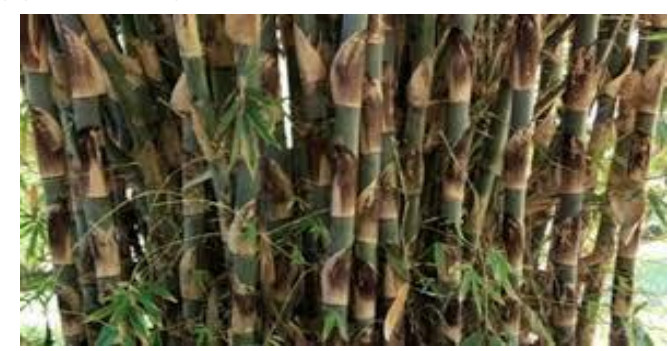

Gambar 1. Bambu Apus 
Tabel 1. Sifat Mekanik bambu Apus [4]

\begin{tabular}{|l|l|}
\hline \multicolumn{1}{|c|}{ Sifat Mekanik } & \multicolumn{1}{c|}{ Mpa } \\
\hline Kekuatan tarik & 53,53 \\
\hline Kekuatan luluh & 32,06 \\
\hline Modulus elastisitas & 9901,96 \\
\hline Kekuatan tekan & 49,41 \\
\hline Kekuatan geser & 3,872 \\
\hline $\begin{array}{l}\text { Kekuatan tarik tegak lurus } \\
\text { serat }\end{array}$ & 2,77 \\
\hline
\end{tabular}

Tabel 2. Hasil percobaan presentase $\mathrm{NaOH}$ terhadap sifat serat [5]

\begin{tabular}{|c|c|l|}
\hline $\begin{array}{c}\mathrm{NaOH} \\
(\% \\
\text { berat })\end{array}$ & $\begin{array}{c}\text { Suhu } \\
{ }^{0} \mathrm{C}\end{array}$ & Sifat serat hasil proses \\
\hline 5 & 70 & $\begin{array}{l}\text { Serat bersifat agak kasar } \\
\text { dan keras, namun serat } \\
\text { dapat terpisah dan } \\
\text { panjang. }\end{array}$ \\
8 & 70 & $\begin{array}{l}\text { Serat lebih lunak dari } \\
\text { percobaan 1. Serat } \\
\text { mudah putus dan rapuh } \\
\text { serat bersifat sangat } \\
\text { lunak. } \\
\text { Namun serat sangat } \\
\text { rapuh dan mudah putus } \\
\text { ketika mengalami } \\
\text { proses pengeringan dan } \\
\text { proses mekanis berupa } \\
\text { pemisahan serat. }\end{array}$ \\
\hline
\end{tabular}

Kekuatan bending komposit[6]

$$
\sigma_{b}=\frac{3 P L}{2 b H^{2}}
$$

Keterangan:

$$
\begin{aligned}
& \sigma_{b}=\text { kekuatan bending }\left(\mathrm{N} / \mathrm{mm}^{2}\right) \\
& \mathrm{P}=\text { beban lentur }(\mathrm{Kg}) \\
& \mathrm{L}=\text { jarak tumpu }(\mathrm{mm}) \\
& b=\text { lebar spesimen }(\mathrm{mm}) \\
& H=\text { tebal spesimen }(\mathrm{mm})
\end{aligned}
$$

Modulus elastisitas

$$
E=\frac{L^{3} m}{4 b H^{3}}
$$

Keterangan:

$$
\begin{aligned}
& \mathrm{E}=\text { Modulus elastisitas }\left(\mathrm{N} / \mathrm{mm}^{2}\right) \\
& \mathrm{L}=\operatorname{Jarak} \text { tumpu spasimen }(\mathrm{mm}) \\
& \mathrm{b}=\operatorname{Lebar} \text { specimen }(\mathrm{mm}) \\
& \mathrm{H}=\text { Tebal specimen }(\mathrm{mm}) \\
& \mathrm{m}=\text { Tangen modulus }(\mathrm{kg} / \mathrm{mm})
\end{aligned}
$$

\section{Metode Penelitian}

Adapun alat dan bahan yang digunakan dalam penelitian ini adalah alat uji misalnya Uji Bending, dan Uji SEM. Gergaji, golok, sikat kawat, digunakan untuk memotong bambu dan mengekstrak bambu menjadi serat. Gunting, cutter, penggaris, kaca digunakan untuk membuat cetakan. Lem tembak, digunakan untuk mencegah kebocoran pada cetakan, Gelas ukur, digunakan untuk mengukur volume resin, dan katalis.

Gerinda, kikir, amplas digunakan untuk membentuk dan menghaluskan bagian spesimen yang masih kasar agar sesuai dengan ukuran standar. Jangka sorong, digunakan untuk mengukur dimensi spesimen Waxs, digunakan untuk memudahkan pelepasan komposit dari cetakan Alkali, digunakan untuk perendaman serat, guna menghilangkan seluiosa yang tinggi. Sedangkan bahan yang digunakan yaitu Resin Poliester, Serat bambu Apus dan Katalis.

\section{Prosedur Penelitian}

1. Bambu di potong sepanjang $40 \mathrm{~cm}$ dan di bersihakan kulit ari/kulit yang berwarna hijau.

2. Belah bambu dan tipiskan kurang lebih 2 mm tebalnya.

3. Rebus bambu dalam air bersih mengunakan suhu $70^{\circ} \mathrm{C}$ selama 3 jam.

4. Keringkan dan sikat dengan Baja.

5. Rendam pada larutan alkali $\mathrm{NaOH}$ selama 2 jam. Serat kemudian dibilas dengan air bersih, kemudian serat dikeringkan di tempat yang tidak terkena sinar matahari langsung.

6. Cetakan dibersihkan, kemudian di oleskan wak atau oli secara merata agar komposit tidak menempel pada cetakan.

7. Membuat campuran resin dengan katalis dengan perbandingan 99:1, kemudian diaduk hingga merata selama 4 menit dan diamkan sesaat agar gelembung dalam campuran resin hilang.

8. Masukkan serat sesuai perbandingan volume yang telah ditentukan, kemudian tuang resin kembali hingga penuh sambil ditekan-tekan untuk menghindari terjadinya gelembung udara. 
9. Tutup cetakan dengan kaca agar permukaan komposit menjadi rata, kemudian diberi beban diatasnya.

10. Biarkan hingga mengering selama \pm 2 jam, kemudian komposit dikeluarkan dari cetakan.

11. Benda uji komposit siap untuk dipotong menjadi spesimen benda uji.

Tabel 3. Komposisi Pembuatan Komposit

\begin{tabular}{|c|c|c|}
\hline $\begin{array}{c}\text { Nomer } \\
\text { Spesimen }\end{array}$ & $\begin{array}{c}\text { Komposisi } \\
\text { Serat }\end{array}$ & $\begin{array}{c}\text { Komposisi } \\
\text { Resin }\end{array}$ \\
\hline 1 & $5 \%$ & $95 \%$ \\
\hline 2 & $10 \%$ & $90 \%$ \\
\hline 3 & $15 \%$ & $85 \%$ \\
\hline 4 & $20 \%$ & $80 \%$ \\
\hline
\end{tabular}

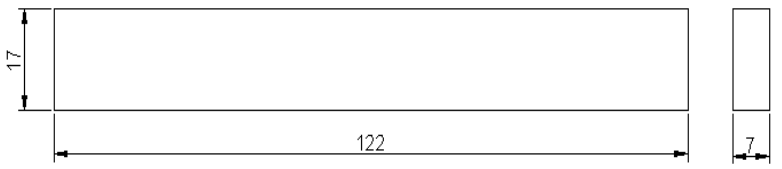

Gambar 2. Ukuran Cetakan Specimen Uji
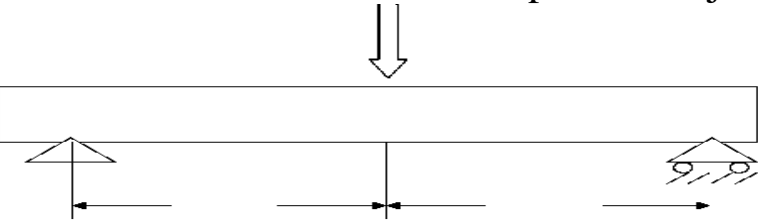

Gambar 3. Pengujian Three Point Bending

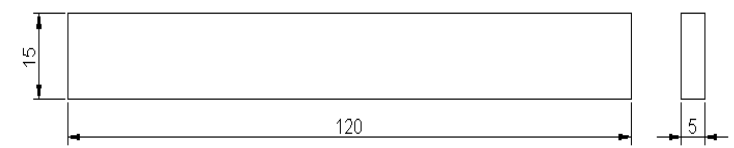

Gambar 4. Specimen Uji Bending

\section{Uji SEM (scanning electron microspope)}

Langkah-langkah yang harus dilakukan dalam pengambilan gambar uji SEM adalah sebagai berikut:

1. Menyiapkan spesimen uji yang akan dianalisis, kemudian merekatkannya pada holder dengan doube tape.

2. Spesimen yang telah dipasang di holder kemudian dibersihkan dengan hand blower.

3. Spesimen dimasukkan dalam mesin coating untuk diberi lapisan tipis berupa gold - poladium.

4. Memasukan specimen kedalam specimen chamber.
5. Pengamatan dan pengambilan gambar pada layar SEM dengan mengatur perbesaran yang diinginkan.

Tabel 4. Jenis pengujian dan Persentase komposisi serat

\begin{tabular}{|l|c|c|c|c|}
\hline $\begin{array}{l}\text { Jenis } \\
\text { pengujian }\end{array}$ & $\begin{array}{c}5 \% \\
\text { serat }\end{array}$ & $\begin{array}{c}10 \% \\
\text { serat }\end{array}$ & $\begin{array}{c}15 \% \\
\text { serat }\end{array}$ & $\begin{array}{c}20 \% \\
\text { serat }\end{array}$ \\
\hline Uji bending & 5 & 5 & 5 & 5 \\
\hline $\begin{array}{l}\text { Cadangan } \\
\text { spesimen uji }\end{array}$ & 1 & 1 & 1 & 1 \\
\hline Jumlah & 6 & 6 & 6 & 6 \\
\hline
\end{tabular}

\section{Hasil dan Pembahasan}

Setelah melakukan pengujian bending dengan standar ASTM D 790-03 maka dapat dikumpulkan data-data pengujian sebagai berikut:

Tabel 5. Hasil Uji Bending Serat Bambu Apus

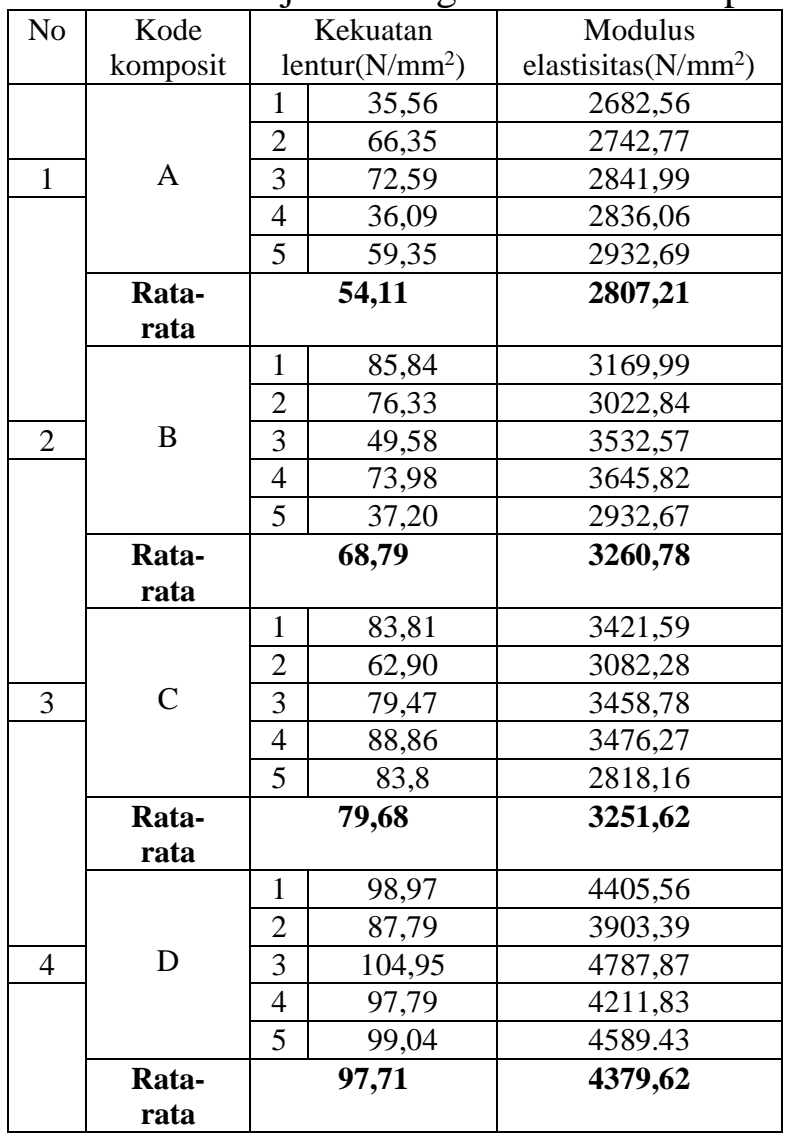

Dari tabel 5 diatas dapat di lihat hasil pengujian kekuatan dan modulus elastisitas bending, dengan fraksi volume 95\%, 90\%, $85 \%$, dan $80 \%$, setiap fraksi atau sampel setelah diambil rata-rata terjadi peningkatan disetiap fraksi volume atau sampel tersebut.

Untuk mempermudah dalam membandingkan kekuatan bending (lentur), 
pada setiap fraksi volume serat, dibuat grafik masing-masing yang berhubungan dengan fraksi volume resin.

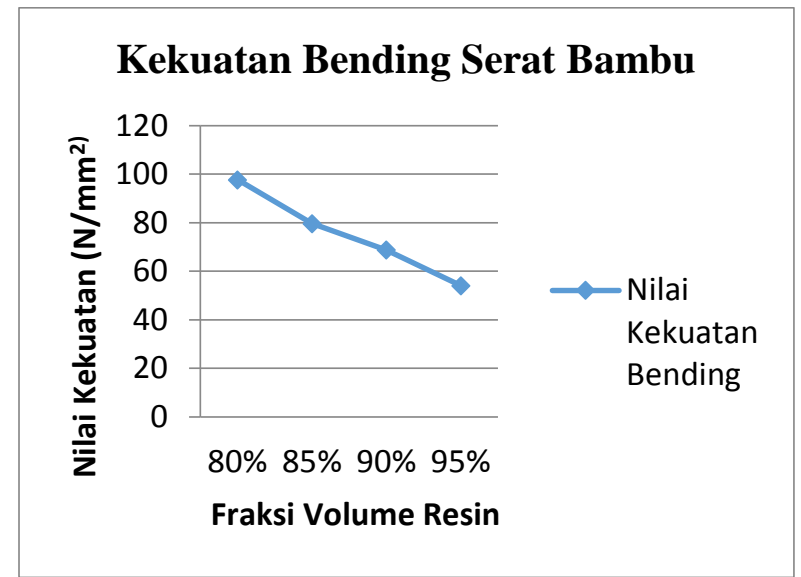

Gambar 5. Grafik Hubungan antara variasi fraksi volume Resin dengan nilai kekuatan Bending

Gambar 5 diatas menunjukan bahwa komposit dengan fraksi volume serat $5 \%$ dan volume resin $95 \%$ menunjukan kekuatan terendah sebesar $54,11 \mathrm{~N} / \mathrm{mm}^{2}$. dan kekuatan tertinggi terdapat pada komposit dengan fraksi volume serat $20 \%$ dan volume resin $80 \%$ dengan nilai kekuatan bending sebesar 97,71 $\mathrm{N} / \mathrm{mm}^{2}$.

Modulus elastisitas komposit serat bambu semakin meningkat seperti pada gambar 6, menunjukan komposit dengan fraksi volume resin 95\% mempunyai nilai modulus elastisitas yang terendah yaitu sebesar 2807,21 N/mm ${ }^{2}$ dan nilai modulus elastisitas tertinggi terdapat pada komposit ngan fraksi volume resin $80 \%$ dengan nilai modulus elastisitas sebesar $4379,62 \mathrm{~N} / \mathrm{mm}^{2}$, Seperti grafik dibawah ini.

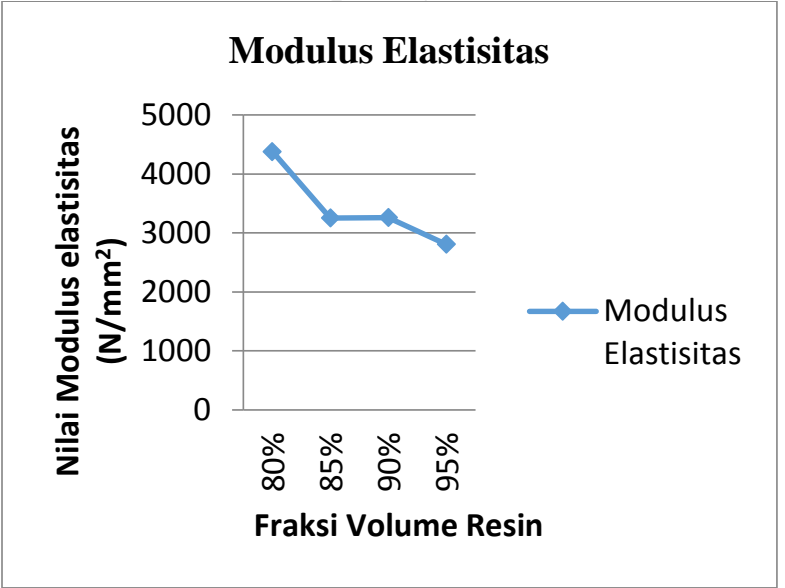

Gambar 6. Hubungan variasi fraksi volume Resin dengan Nilai Modulus Elastisitas
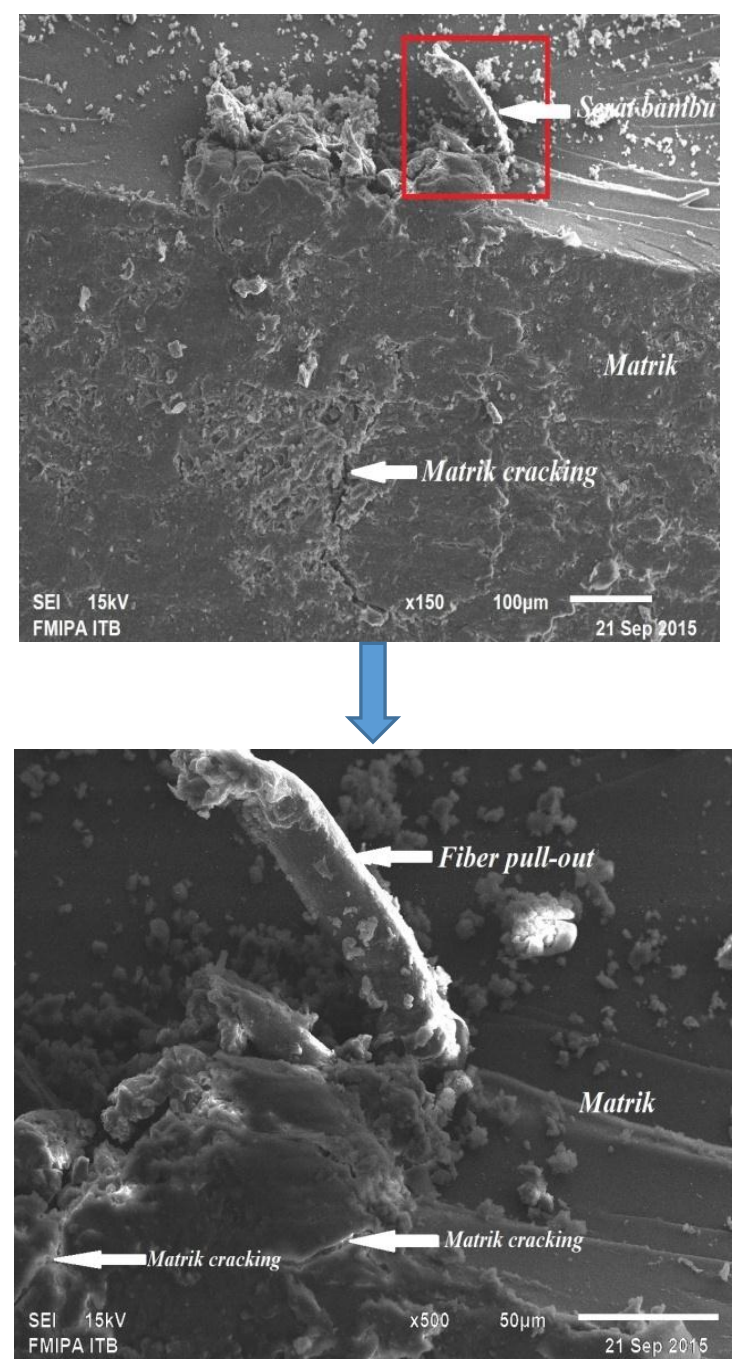

Gambar 7. Penampang patahan komposit $95 \%$ resin setelah di uji bending dengan pembesaran 150x pembesaran 500x

Dari gambar 7 adalah penampang patahan komposit $95 \%$ yang memiliki nilai kekuatan bending terendah yaitu $54,11 \mathrm{~N} / \mathrm{mm}^{2}$. Jika dilihat, patahan komposit didominasi oleh matrik, matrik mengalami cracking (retak), dan fiber pull out. fiber pull out adalah serat yang putus dan terlihat keluar atau menjulur pada penampang patahan, fiber pull out terjadi akibatkan pada saat pengujian bending matrik kurang kuat mengikat serat sehingga serat terlepas dari matrik. Dan secara mikro tidak dijumpai void didalam komposit $95 \%$ tesebut, jika fiber pull out dapat diminimalisir, maka akan didapatkan komposit serat bambu dengan kekuatan bending yang tinggi.sedangkan matrik cracking, yaitu retaknya matrik akibat matrik bersifat getas. Hal ini perlu menjadi perhatian, walaupun sifat getas menyebabkan 
kekuatan meningkat, namun jika retakan yang terjadi melebihi batas akan menyebabkan debonding.

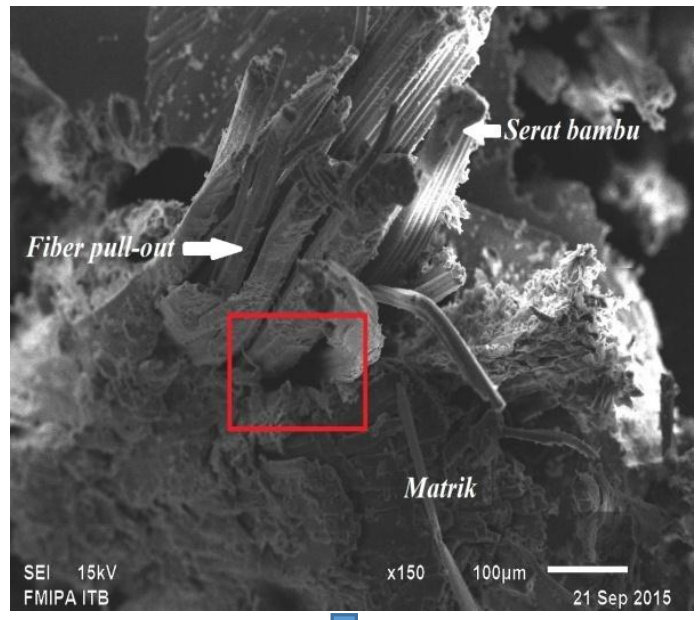

(a)

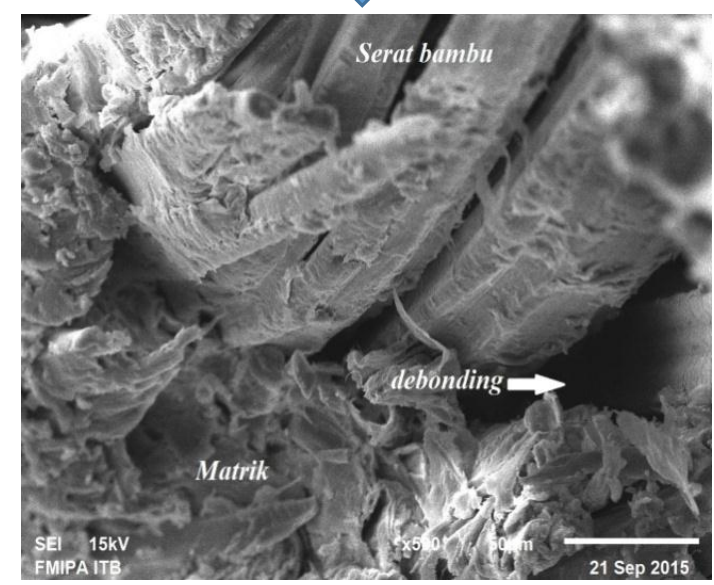

(b)

Gambar 8 Penampang patahan komposit $80 \%$ resin setelah di uji bending bending (a) dengan pembesaran 150x (b) pembesaran $500 \mathrm{x}$

Pada penampang patahan komposit dengan fraksi volume 80\%: $20 \%$ adalah komposit mempunyai nilai kekuatan tertinggi dengan nilai kekuatan bending sebesar 97,71 $\mathrm{N} / \mathrm{mm}^{2}$. Pada fraksi tersebut masih terlihat pada beberapa titik terjadi kegagalan pull out yang di tunjukan pada gambar 4.6,selain ditemukan pull-out pada komposit yang mengurangi kekuatan bending, ternyata setelah dilakuan pembesaran yang berbeda terlihat debonding pada komposit tersebut. Debonding adalah lepasnya daya ikat antara serat dan matrik, debonding terjadi akibat tidak kuatnya daya ikat antara serat dengan matrik sehingga saat terjadi tekanan matrik terlepas dari serat.

\section{Kesimpulan}

1. Pada spesimen uji bending untuk ke 4 variasi fraksi volume yaitu $95 \%: 5 \%$, 90\% : $10 \%, 85 \%: 15 \%$ dan $80 \%: 20 \%$ resin dan serat sangat berbeda, kekuatan komposit serat bambu meningkat seiring dengan meningkatnya fraksi volume serat dan berkurangnya volume matrik atau resin. Variasi fraksi volume serat mempengaruhi kekuatan bending komposit, dimana kekuatan bending komposit tertinggi diperoleh pada komposit dengan fraksi volume resin $80 \%$ dan serat $20 \%$ yaitu sebesar $97,71 \mathrm{~N} / \mathrm{mm}^{2}$, sedangkan nilai kekuatan bending terendah diperoleh pada dengan fraksi volume resin $95 \%$ dan serat $5 \%$ yaitu sebesar $54,11 \mathrm{~N} / \mathrm{mm}^{2}$.

2. Pada pola patahan komposit bending yang di uji secara mikro atau menggunakan SEM (scaning electro miscroscope) volume resin $95 \%$ dan $80 \%$ menunjukan debonding dimana lepasnya daya ikat serat dengan matrik. Matrik cracing (ratak) dan fiber pull- out. Semakin sedikit pull-out yang terjadi , maka semakin baik kekuatan komposit tersebut. Pull-out mengindikasikan daya ikat serat dan matrik yang rendah. Sedangkan void juga berpengaruh terhadap kekuatan. Dengan adanya void didalam komposit kekuatan kompositpun akan berkurang.

\section{Daftar Pustaka}

[1] Daut Johan AbanatJ, dkk. 2012." Pengaruh Fraksi Volume Serat Gebang (Corypa Utan Lamarck) Terhadap Sifat Mekanik Pada komposit”. Jurnal rekayasa mesin.

[2] Manuputty M, dkk. 2010. “ Pemanfaatan Material Bambu Sebagau Alternatif Bahan Komposit Pembuat Kulit Kapal Pengganti Kayu untuk Armada Kapal Rakyat Yang Beroperasi Didaerah Maluku”. Jurnal Teknologi, Vol.7 No 2.

[3] Setiawan T, 2015. "Pengaruh Komposisi Resin Poliyester Terhadap Kekerasan Dan Kekuatan Tarik Komposit Yang Diperkuat Serat Pelepah Kelapa Sawit". 
[4] Hirmawan B, dkk. 2010."Sifat Mekanik Komposit Serat Bambu Akibat Pengaruh Musim Hujan Dengan /Tanpa Pelapisan”. Jurusan Teknik Fisika ITS.

[5] Nurkertamanda D, dkk. 2012 Disain Proses Pembentukan Serat Bambu Sebagai Bahan Dasar Produk Industri Kreatife Berbahan Dasar Serat Pada UKM”. J@ti Undip, Vol VII, No 3.

[6] Andri Purwanto D, dkk. 2010.

"Karakterisasi Komposit Berpenguat Serat Bambu Dan Serat Gelas Sebagai Alternatif Bahan Baku Industri”. FTI, ITS Surabaya. 